\section{Shared Y chromosome repetitive DNA sequences in stallion and donkey as visualized using whole-genomic comparative hybridization}

\author{
J. Gosálvez, ${ }^{1}$ F. Crespo, ${ }^{2}$ J.L. Vega-Pla, ${ }^{2}$ \\ C. López-Fernández, ${ }^{1}$ E.I. Cortés- \\ Gutiérrez, ${ }^{3}$ M.I. Devila-Rodriguez, ${ }^{3}$ \\ R. Mezzanotte ${ }^{4}$
}

'Department of Biology, Genetics Unit, Universidad Autonoma de Madrid

(UAM), Madrid, Spain; ${ }^{2}$ Veterinary

Services of the Spanish Army (FESCCR-

Ministerio de Defensa), Avila, Spain;

${ }^{3}$ Department of Genetics, Northwest

Research Centre of Biology, Mexican

National Institute for Health, Monterrey,

Mexico; ${ }^{4}$ Department of Biomedical

Sciences and Biotechnology, Section of

Genetics, Cittadella Universitaria,

Monserrato (Cagliari), Italy

\begin{abstract}
The genome of stallion (Spanish breed) and donkey (Spanish endemic Zamorano-Leonés) were compared using whole comparative genomic in situ hybridization (W-CGH) technique, with special reference to the variability observed in the Y chromosome. Results show that these diverging genomes still share some highly repetitive DNA families localized in pericentromeric regions and, in the particular case of the $\mathrm{Y}$ chromosome, a sub-family of highly repeated DNA sequences, greatly expanded in the donkey genome, accounts for a large part of the chromatin in the stallion $Y$ chromosome.
\end{abstract}

\section{Introduction}

The chromosome number in the donkey (Equus asinus) is $2 \mathrm{n}=62,{ }^{1,2}$ but $2 \mathrm{n}=64$ in the horse (Equus caballus). ${ }^{3}$ The two species are both evolutionarily and genetically related. In fact, a certain level of bidirectional sex genome compatibility does exist: when a male donkey and a female horse mate, they produce a mule, and when a stallion mates with a female donkey, a hinny is produced. Both are usually sterile, but in some cases a certain level of genome compatibility is found and female mules get pregnant, although embryo loss is quite frequent. ${ }^{4}$

Among the different DNA sequences making up a eukaryotic genome, highly repetitive DNA sequences are considered good evolutionary markers, due to their capacity to change rapidly as compared to single gene sequences. ${ }^{5}$ These DNAs are commonly associated with satellite DNA fractions (sat-DNA) and are usually localized in constitutive heterochromatin regions. Their ability to rapidly alter their base composition can produce rapid divergence in equivalent chromosome domains. This divergence can easily be observed, both within species and among closely related species. This is the case, for example, with alphoid DNA sequences in humans and other primates. ${ }^{6}$ During the last few years, our research group has developed a method, whole comparative genomic hybridization (W-CGH), which allows the identification of chromosomal polymorphisms related to sat-DNAs localized in constitutive heterochromatin. ${ }^{7}$ W-CGH acts by detecting polymorphisms on the basis of competition between two different genomic DNAs in the experimental conditions of in situ hybridization, without subtraction of highly repetitive DNA sequences. This technique has been used in several related species and/or individuals or populations belonging to the same species. ${ }^{7-9}$ These differences are easily assessed when the $\mathrm{Y}$ chromosome in boar is targeted. ${ }^{9}$ On the contrary, this differentiation was not noticeable when different ram breeds were compared. ${ }^{10}$ Given the geneticallyimposed lack of homologous recombination on $Y$ chromosomes, the rate of sequence evolution within these chromosomes is usually higher than that in autosomes. ${ }^{11,12}$ Furthermore, the Y chromosome tends to be unusually rich in repetitive DNAs, due to both transposable elements and tandem arrays of satDNA sequences. ${ }^{12,13}$

The aim of this preliminary work was to characterize donkey and horse Y chromosome highly repetitive DNA sequences, to understand resemblances and differences between the two Y chromosomes isolated approximately 2 MY ago. ${ }^{14,15}$

\section{Materials and Methods}

Whole genomic DNA was obtained from the peripheral blood of one stallion and one male donkey. The stallion was a pure Spanish breed and the donkey a Spanish breed (ZamoranoLeonés) in danger of extinction. Peripheral blood lymphocytes were extracted and cultured for $72 \mathrm{~h}$ in RPMI 1640 (Gibco, Invitrogen Corporation, Carlsbad, CA, USA). This medium was supplemented with $1.5 \%$ phytohaemagglutinin, 10\% fetal calf serum and antibiotics. Chromosomes were obtained using cells arrested at metaphase with colcemid (10
Correspondence: Jaime Gosálvez, Department of Biology, Unit of Genetics, Universidad Autónoma de Madrid, 20849 Madrid, Spain.

E-mail: jaime.gosalvez@uam.es

Key words: mammalian genome, mammalian cytogenetics, genome evolution, comparative genomics.

Acknowledgements: work was supported by BFU 2007-66340/BFI (Ministerio de Education y Ciencia, SPAIN). The authors also thank Ms. Mary Ann Groeneweg for checking the English style of the manuscript.

Received for publication: 28 September 2009 Accepted for publication: 28 November 2009.

This work is licensed under a Creative Commons Attribution 3.0 License (by-nc 3.0).

(C) Copyright J. Gosálvez et al., 2010 Licensee PAGEPress, Italy

European Journal of Histochemistry 2010; 54:e2 doi:10.4081/ejh.2010.e2

$\mathrm{mg} / \mathrm{mL}$ ) for 90 minutes. Chromosome slides were prepared by exposing the cell suspension to $0.075 \mathrm{M} \mathrm{KCl}$ for 20 minutes and rapidly fixing it in fresh fixative (methanol-acetic $3: 1$ ). To obtain metaphase cells, fixed lymphocytes were spread onto clean slides and allowed to dry. For the W-CGH experiment, stallion and donkey DNAs were extracted according to standard procedures. The final concentration of each DNA sample was carefully measured using a DNA-spectrophotometer (AmershamPharmacia Biotech, Piscataway, NJ, USA). Two DNA samples of equivalent concentration were labelled with biotin-14-dUTP (H: Horse) and digoxigenin-11-dUTP (D: Donkey), employing a commercial nick translation kit (Roche Diagnostics Corporation, Indianapolis, IN, USA). After DNA labelling, probe size fragments were tested to be in the range of 600 2000 bp in a $1 \%$ agarose gel. Both DNA probes were mixed at equal concentrations and the resulting mixed probe was precipitated with ethanol. After air drying, the probe was dissolved in hybridization buffer $(50 \%$ formamide-2xSSC/10\% dextran sulphate-2xSSC, $\mathrm{vol} / \mathrm{vol}$; $\mathrm{pH} 7$ ) to a final concentration of 20 $\mathrm{ng} / \mu \mathrm{L}$, denatured at $70^{\circ} \mathrm{C}$ for 10 minutes and placed on ice for 5 minutes. For FISH, metaphase slides were incubated in 2XSSC at $37^{\circ} \mathrm{C}$ for 60 minutes and dehydrated in $70 \%$, $85 \%$ and $100 \%$ ethanol. After air drying, slides were denatured in $70 \%$ formamide/ $2 \mathrm{XSSC} \mathrm{pH}$ 7 at $70^{\circ} \mathrm{C}$ for 2 minutes and dehydrated again. In this experimental approach, stallion chromosomes were used for probe landing. The DNA probe was applied to the slides and hybridized at $37^{\circ} \mathrm{C}$ in a moist chamber 
overnight. After hybridization, slides were washed in $50 \%$ formamide at $42^{\circ} \mathrm{C}$ for 15 minutes and in $2 \mathrm{XSSC}$ at $37^{\circ} \mathrm{C}$ for 8 minutes. A non-specific antibody blocking solution [BSA $10 \%$ (wt/vol)/Tween 20, 0.05\% (vol/vol)/2XSSC, $\mathrm{pH} 7$ ] was applied for 5 minutes at $37^{\circ} \mathrm{C}$. Slides were then incubated for 25 minutes at $37^{\circ} \mathrm{C}$ in the antibody solution, with a single layer of FITC-avidin and rhodamine anti-digoxigenin antibodies (Appligene- Oncor, Illkirch, France), for simultaneous localization of the two probes in green (G) and red (R), respectively (Stallion probe + Donkey probe). Finally, slides were mounted with anti-fade solution (Vectashield). FISH experiment samples were counterstained with DAPI (4', 6-diamidino-2phenylindole) (100 ng/ $/ \mathrm{L})$. DAPI counterstaining blocks yellow fluorescence produced by a similar contribution of both DNA probes on the chromosome arms, but its use is advisable, as it enhances contrast with constitutive heterochromatin labelling.

Slides were analyzed using a Leica DMLB fluorescence microscope equipped with a charge-coupled device camera (Leica DFC350 FX, Leica Microsystems) with three independent green, red and blue filters. Images were captured as grey level .tiff files. Files were merged using using Adobe-Photoshop CS3 (Adobe Systems Incorporated, USA).

\section{Results and Discussion}

When W-CGH was carried out on stallion chromosomes using an equimolar genomic DNA probe obtained from horse and donkey, all chromosomes showed varying quantities of green fluorescence in the constitutive heterochromatin of each autosome. This is the result expected, given that the chromosomal strip for DNA probe landing was stallion chromosomes. In some autosomes, there was only a green signal (arrows in Figure 1a), while in others the green signal co-localized with a red signal (contribution of expanded DNA sequences in donkey; arrowhead in Figure 1a). Interestingly, after W-CGH, the Y chromosome split into three different chromosome domains (Figure 1a). First, a proximal region was identified. This region resembles the chromosome domain related to kinetochore activity, and for this reason was identified as the proper centromeric region (H-CR; Figure $1 \mathrm{~b}$ ). $\mathrm{H}-\mathrm{CR}$ is small as compared to the rest of the Y chromosome and, in this case, showed only intense green fluorescence. Additionally, an interstitial, highly expanded and pericentromeric region (H-PR; Figure 1b), showing red fluorescence, was present. Finally, a distal region (H$\mathrm{DR}$; Figure 1b) which fluoresces in blue because of the counterstaining effect was


\section{Horse}



Donkey
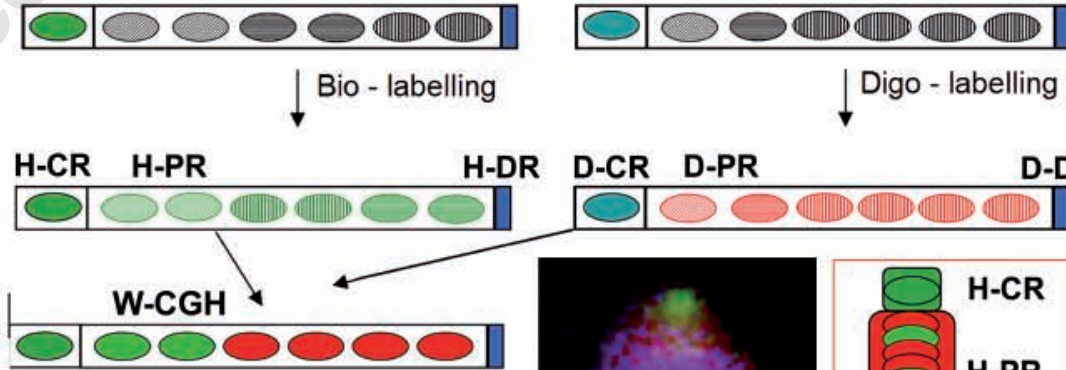

Stallion chromosomal strip

for probe landing

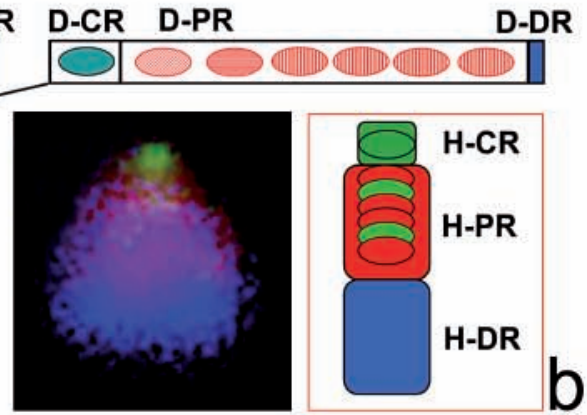

Figure 1. Panel 1a shows metaphase chromosomes of stallion after hybridization with an equimolar genomic DNA probe obtained using whole stallion (labelled in green) and donkey genomic DNA (labelled in red). Note that all autosomes reveal FISH signal corresponding to the stallion DNA labelling colour (green, see standard arrows), while red (donkey) is present in some autosomes (arrowhead) and the Y chromosome. A diagram showing the possible expansion and divergence among centromeric and pericentromeric DNA subfamilies is shown in panel $b$. Colour code for each species is maintained. 
observed. H-DR before DAPI counterstaining showed yellow fluorescence due to the equivalent contribution of both DNA probes. In the W$\mathrm{CGH}$ environment, this is the normal staining response in chromosomal arms. ${ }^{7}$ In short, the $\mathrm{Y}$ chromosome in this stallion is principally compartmentalized in three different chromosome domains, where H-CR is mainly constructed with specific DNA families from the horse, while H-PR reveals a massive presence of highly-expanded donkey DNA sequences which are also present in the stallion, although at lower intensity. H-DR remains as the euchromatic DNA common to both species. This chromosome compartmentalization evident in the stallion chromosome is very similar to the GTG-banded Y chromosome in donkey, as represented by Raudsepp et al. ${ }^{16}$

Results obtained in the present preliminary study clearly show that the stallion and donkey still share some highly repetitive DNA families, although the expansion level of specific sub-chromosomal domains varies and is characteristic for each species. This tendency is observed in most autosomes, but in the particular case of the stallion Y-chromosome, some peculiar DNA arrangements (H-PR) are conserved, while appearing to have greatly expanded during the evolution of the donkey Ychromosome (D-PR; Figure 1b). An alternative explanation is that DNA arrangements in $\mathrm{H}$ $\mathrm{PR}$, equivalent to those in D-PR, were partially lost during evolutionary processes regarding the Y-chromosome. In both cases, the absence of legitimate recombination would facilitate this process of differential DNA expansion or contraction.

The results showing differential expansion of highly repetitive satellite DNA families are congruent with the library hypothesis postulated by Fry and Salser, ${ }^{17}$ which suggested that major sat-DNAs found in a group of extant species with any degree of phylogenetic relationship were already present in a common ancestor. These DNA sequences formed a pool of sat-DNA sequences at low copy number, as a primordial sat-DNA library. This idea is depicted for the stallion and donkey Y-chromosome in the diagram shown in Figure 1b. In the case of the $\mathrm{Y}$ chromosome in stallion and donkey (sub-chromosomal regions H-CR or D-CR), this divergence was absolute. However, in the case of H-PR and D-PR, these species-specific sat-DNA profiles can be obtained by a change in the copy number of sat-DNAs, without major variation in their sequence or obvious quantitative change. ${ }^{18,19}$ Alternatively, as in the majority of cases, the same situation can occur as a consequence of simultaneous change in both parameters. ${ }^{20}$ For instance, W-CGH performed using two closely related grasshoppers, produces results on some autosomes similar to those reported here for the Y chromosome. ${ }^{8}$
The results obtained in grasshoppers were identical irrespective of the species employed as the chromosomal strip for probe landing. This fact suggested that, in addition to heterochromatic compartmentalization on constitutive heterochromatin, variation in sat-DNA family copy number, rather than sequence divergence, may account for the differential presence of DNA families in the species compared.

In addition to the genome macro-variations concerning chromosome number and morphology described for horse and donkey, it is interesting to stress that eight centromere repositioning episodes occurred when the karyotypes of zebra, horse and stallion were compared. ${ }^{21}$ This phenomenon presupposes the inactivation of old centromeric regions, accompanied by the rapid loss of centromeric satellite DNA and by the dispersal of pericentromeric duplications over a relatively wide area of the chromosome. ${ }^{22,23}$ This scheme of genome re-patterning is congruent with our observations regarding sat-DNA expansion and contraction in the Y, as well as other autosomes and the $\mathrm{W}$ $\mathrm{CGH}$, and could probably be used as a quick test to study this phenomenon.

Finally, the differences in sat-DNA found in some autosomes must be taken into account in explaining the sterility observed when hybrids are produced. Horse-donkey hybrids (mules and hinnies) exhibit massive meiotic dysfunction at the primary spermatocyte stage, and a large part of this dysfunction is caused by the incompatibility of synaptonemal pairing between paternal and maternal chromosomes, resulting in the total arrest of spermatogenesis. ${ }^{24,25}$ This aspect is of interest, as it is known that differences in heterochromatin content in pericentromeric or distal chromosome regions, even within the same species, cause chiasma redistribution due to misleading chromosome pairing. ${ }^{26}$

\section{References}

1. Benirschke K, Brownhill LE, Beath MM. Somatic chromosomes of the horse, the donkey and their hybrids, the mule and the hinny. J Reprod Fertil 1962;4:319-26.

2. Trujillo J, Stenius C, Christian LC, Ohno S. Chromosomes of the horse, the donkey and the mule. Chromosoma 1962;13:243-8.

3. Richer CL, Power MM, Klunder LR, et al. Standard karyotype of the domestic horse (Equus caballus). Committee for standardized karyotype of Equus caballus. The Second International Conference for Standardization of Domestic Animal Karyotypes. Hereditas 1990;112:289-93.

4. Ryder OA, Chemnick LG, Bowling AT, Benirschke K. Male mule foal qualifies as the offspring of a female and jack donkey. J Hered 1985;76:379-81.

5. Archidiacono N, Antonacci R, Marzell R, et al. Comparative mapping of human alphoid sequences in great apes using fluorescence in situ hybridization. Genomics 1995;25:477-84.

6. Waye JS, Willard HF. Nucleotide sequence heterogeneity of alpha satellite repetitive DNA: a survey of alphoid sequences from different human chromosomes. Nucleic Acids Res 1987;15:7549-69.

7. Pita M, Fernández JL, Gosálvez J. Wholecomparative genomic hybridisation (W$\mathrm{CGH})$. 1. The quick overview of repetitive sequences in a genome. Chromosome Res 2003;11:673-9.

8. Pita M, Zabal-Aguirre M, Arroyo F, et al. Arcyptera fusca and Arcyptera tornosi repetitive DNA families: whole-comparative genomic hybridization (W-CGH) as a novel approach to the study of satellite DNA libraries. J Evol Biol 2008;21: 352-61.

9. Pita M, Garcia-Casado P, Toro MA, Gosálvez J. Differential expansion of highly repeated sequences in the swine subgenomes. J Zool Syst Evol Res 200; 46:186-9.

10. Davila-Rodriguez MI, Cortés-Gutiérrez EI, López-Fernández C, et al. Whole comparative genomic hybridization in domestic sheep (Ovis aries) breeds. Cytogenet Genome Res 2009;124:19-26.

11. Rice WR. Evolution of the Y chromosome in animals. Biosciences 1999;46:331-43.

12. Charlesworth, B. The organization and evolution of the $\mathrm{Y}$ human chromosome. Genome Biology 2003;4:226.

13. Ferguson-Smith MA, Trifonov V. Mammalian karyotype evolution. Nat Rev Genet 2007;8:950-62.

14. Oakenfull EA, Clegg JB. Phylogenetic relationships within the genus Equus and the evolution of alpha and theta globin genes. J Mol Evol 1998;47:772-83.

15. Oakenfull EA, Lim H, Ryder 0. A survey of equid mitochondrial DNA: implications for evolution, genetic diversity and conservation of Equus. Conserv Genet 2000;1:34155 .

16. Raudsepp T, Christensen K, Chowdhar BP. Cytogenetics of donkey chromosomes: nomenclature proposal based on GTGbanded chromosomes and depiction of NORs and telomeric sites. Chromosome Res 2000;8:659-70.

17. Fry K, Salser W. Nucleotide sequences of HS-alpha satellite DNA from kangaroo rat Dipodomis ordii and characterization of similar sequences in other rodents. Cell 1977;12:1069-84.

18. Mestroviç N, Plohl M, Mravinac B, Ugarcoviç D. Evolution of satellite DNAs 
from the genus Palorus-evidence for the library hypothesis. Mol Biol Evol 1998; 15:1062-8.

19. Arnason U, Gretarsdottir S, Widegren B. Mysticete (baleen whale) relationships based upon the sequence of the common cetacean DNA satellite. Mol Biol Evol 1992;9:1018-28.

20. Nijman IJ, Lenstra JA. Mutation and recombination in cattle satellite DNA: a feedback model for the evolution of satellite DNA repeats. J Mol Evol 2001;52:361-71.
21. Carbone L, Nergadze SG, Magnani E, et al. Evolutionary movement of centromeres in horse, donkey, and zebra. Genomics 2006;87:777-82.

22. Montefalcone G, Tempesta S, Rocchi M, Archidiacono N. Centromere repositioning. Genome Res 1999;9:1184-8.

23. Ventura M, Archidiacono N, Rocchi M. Centromere emergence in evolution. Genome Res 2001;11:595-9.

24. Chandley AC, Jones RC, Dott HM, et al. Meiosis in interspecific equine hybrids. I.
The male mule (Equus asinus $x$ E. caballus) and hinny (Equus caballus $\mathrm{x}$ E. asinus). Cytogenet Cell Genet 1974;13:330-41.

25. Landime e Alvarenga FC, Bortolozzi J. Ultrastructure of the Hinny (Equus asinus $\mathrm{x}$ Equus caballus) seminiferous ephitelium. Anat Histol Embryol 1994;23:343-51.

26. Gosálvez J, Garcia de La Fuente R. The effect of a deficiency on chiasma distribution and frequency in a male of Stauroderus scalaris (Orthoptera). Caryologia 1981; 34:473-81. 